\title{
Revezamento teoria e prática na análise da escola pública democrática
}

\section{Theory and practice relay in democratic public school analysis}

\author{
Graziela Zambão Abdian*
}

\begin{abstract}
RESUMO
Com o objetivo de contribuir com as discussões da Política e Gestão da educação e escolar, o texto apresenta elementos para a análise das possibilidades de experiências da escola pública democrática, por meio do revezamento teoria e prática. Para tal, relatamos resultados de pesquisas que analisaram dissertações, teses e artigos publicados em periódicos sobre a temática gestão democrática. Além disso, apontamos desafios para a área com a busca de novos horizontes conceituais que nos possibilitem compreender a complexidade da gestão educacional escolar. Finalmente, exploramos os conceitos Política e Democracia por meio de autores/as que nos possibilitam repensar as relações entre teoria e prática presentes nas pesquisas comumente publicadas na área.
\end{abstract}

Palavras-chave: Escola democrática. Política. Democracia radical e plural. Revezamento teoria e prática.

\begin{abstract}
With the aim of contributing to the discussions of politics and management of education in the school system, the text presents elements for the analysis of the possibilities of experiences of the democratic public school, through the alternation of theory and practice. To that end, we report the results of researches that analyzed dissertations, theses and articles published in periodicals about the democratic management theme. We also identified challenges for the area, searching for new conceptual horizons to understand the complexity of school educational management and, at last, we explore the concepts of "politics" and "democracy" through authors that allow us
\end{abstract}

* Universidade Estadual Paulista Júlio de Mesquita Filho (UNESP). Marília, São Paulo, Brasil. E-mail: graziela.maia@gmail.com. https://orcid.org/0000-0001-5698-000X 
to rethink the relations between theory and practice present in the research commonly published in the area.

Keywords: Democratic school. Politics. Radical and plural democracy. Alternation between theory and practice.

\section{Introdução}

Fala-se muito hoje em "diálogo" e "deliberação", mas qual o significado de tais palavras no campo político se não existe nenhuma escolha real ao nosso alcance e se os participantes do debate não são capazes de decidir entre alternativas claramente diferenciadas?

Chantal Mouffe

Em novembro de 2017, participei de uma mesa-redonda denominada "Financiamento da Educação em tempos de crise e os desafios do Plano Nacional de Educação"1 e, ao final, do debate, uma das questões, formulada por uma ex-secretária de educação de município do interior paulista, chamou-me a atenção: “Após sua explanação sobre gestão democrática nos Planos nacional, estadual paulista e municipais, você considera que deveria haver um modelo de gestão democrática vindo do governo federal, ou seja, deveríamos ter uma lei que regulamentasse a gestão democrática em âmbito nacional sendo válida para todos os estados, municípios e escolas?" As nossas respostas, integrantes da mesa, foram divergentes e com elas permaneci refletindo sobre conceitos, práticas e produções já realizadas por mim e sob minha orientação, com o Centro de Estudos e Pesquisas em Administração da Educação (CEPAE), com sede na Universidade Estadual Paulista (UNESP/Marília).

Trazendo para o debate conceitos que fundamentam e estruturam a área - Político, Política, Democracia -, tenho como objetivo, com a produção deste artigo, contribuir com as discussões da Política e Gestão da educação e escolar.

1 A mesa-redonda ocorreu durante o "Congresso Nacional de Políticas Educacionais da Unoeste", realizado na Universidade do Oeste Paulista, entre os dias 22 e 23 de novembro de 2017, com minha participação e do professor José Marcelino de Rezende Pinto (USP-Ribeirão Preto). Este contemplou a temática do financiamento no Plano Nacional de Educação e eu explorei a temática da gestão democrática nos Planos nacional, estadual e municipais, ambos no contexto de crise política e econômica. 
Para isto, percorrerei um caminho, dividido em três partes, que me permita, nas considerações finais, responder à profissional da educação presente no congresso.

Destaco que este artigo é escrito no momento em que estamos encerrando uma pesquisa, sob minha coordenação, com a participação de pesquisadores de iniciação científica, mestrado e doutorado e, por tal razão, serão considerados dados parciais, publicados nos últimos dois anos (2016 e 2017).

Primeiramente, realizo uma síntese de parte da produção de minha autoria e coautoria de orientandos do último ano (2017), a qual permitirá situar nossa preocupação com a produção do conhecimento e as relações teoria e prática, estas compreendidas, neste artigo, como relações de revezamento. Em seguida, faço uma análise dos resultados de pesquisas de integrantes do grupo que exploraram a produção do conhecimento sobre gestão democrática em teses, dissertações e artigos em revistas qualificadas, com o objetivo de destacar como ela - gestão democrática - e as relações teoria e prática são concebidas pelos autores da área. Na terceira parte, discutimos três conceitos - Político, Política e Democracia - em uma perspectiva teórica que permita integrar as discussões das partes anteriores e, também, responder à questão narrada no início desta Introdução.

\section{Revezamento teoria e prática e as pesquisas em gestão escolar}

O desenvolvimento do projeto de pesquisa intitulado "A (re)configuração da Gestão educacional/escolar após período crítico dos anos 1980" tem nos permitido, como pesquisadores em construção, coletar, sistematizar, analisar e produzir conhecimento com a intenção de questionar a construção da área - da qual também participamos - no que diz respeito, principalmente, às relações que ela estabelece entre teoria e prática ${ }^{2}$.

No âmbito da pesquisa, realizamos sistematização e análise de produções da área da Política e Administração/Gestão da educação e escolar e lançamos limites do conhecimento e o que entendemos serem seus principais desafios (ABDIAN; NASCIMENTO; SILVA, 2016). A primeira etapa - análise da produção - possibilitou constatarmos a existência de um pensamento binário característico da área: administração empresarial e gestão democrática (especificidade da escola), sendo as duas práticas teóricas caracterizadas pela pres-

2 A partir deste momento no texto utilizarei a primeira pessoa do plural porque se tratou de um percurso coletivo dos integrantes do CEPAE. 
crição do que deve fazer a escola. A segunda etapa - constatação dos limites e dos desafios - possibilitou-nos, de maneira autocrítica, apontar como principal desafio para nós, pesquisadores da área, a necessidade de repensarmos a própria função da teoria e a forma que ela se constrói, dessa forma, desenhou-se, também, a necessidade de buscarmos novos horizontes teórico-metodológicos para nossas pesquisas. Naquele momento, relatamos nossas experiências com alguns autores (FOUCAULT, 1982; BOURDIEU, 2004; CERTEAU, 1994; SOUSA SANTOS, 1999) que nos possibilitaram “"...] discutir os rumos da teoria crítica do campo da administração/gestão educacional/escolar e as dificuldades de ela se construir de forma a estabelecer novas relações entre teoria e prática, que fujam ao modelo prescritivo." (ABDIAN; NASCIMENTO; SILVA, 2016, p. 473). Enfim, com Canário (2006), estabelecemos como perspectiva a produção do conhecimento que fuja da tentação normativa e prescritiva.

No ano seguinte, com a mesma preocupação norteadora - relações teoria e prática na área - e com o objetivo de analisar os sentidos que estão em construção na e pela escola sobre gestão e qualidade, buscamos elementos que nos permitissem visualizar a produção do conhecimento de forma não prescritiva (ABDIAN; NASCIMENTO, 2017). Defendemos a tese, coerente com o escrito anterior, "[...] de que os sentidos em construção pelos integrantes das escolas públicas de diferentes sistemas municipais não se encerram em quadros teórico-metodológicos fechados, que também não se põem ao diálogo e à construção de novas balizas" [...] e assim, com Sousa Santos (1999), “[...] defendemos a ideia de que precisamos buscar horizontes teórico-metodológicos que permitam a aproximação da escola em novas bases de construção do conhecimento científico." (ABDIAN; NASCIMENTO, 2017, p. 297). Somados aos resultados anteriores, os dados coletados por meio de observação e entrevistas semiestruturadas em diversas escolas de educação municipal nos impuseram a busca por novas análises, que pudessem dar conta da multiplicidade encontrada no cotidiano e, com Gallo e Figueiredo (2015), compreendemos o cotidiano escolar como "educação menor" (instituinte), como região de proliferação de diferenças e de linhas de fuga em relação à educação maior (instituída, estatal).

Em seguida, a análise de três perspectivas teórico-metodológicas diferentes sobre o estudo da escola permitiu-nos identificar, apesar das particularidades dos respectivos autores, sentidos semelhantes que as três atribuem à política $\mathrm{e}$ à gestão, constituindo-se como limites da forma de compreender o cotidiano, pois elas entendem que a "[...] a política seja feita em âmbito governamental e que a gestão se constitua como as formas de trabalhar a política, recriando-a, reproduzindo-a e/ou anulando-a." (ABDIAN; ANDRADE; PARRO, 2017, p. 740). De forma propositiva e nos subsidiando em Mouffe $(2005,2015)$, apresentamos a possibilidade de a gestão ser concebida não apenas como mediadora 
de uma dada política educacional, mas, sobretudo, como articuladora de novas hegemonias.

Os resultados apresentados articulam diversas categorias - cotidiano escolar, política, gestão - em torno de uma mesma preocupação, qual seja: como a área da Política e Administração/Gestão da educação e escolar estabelece as relações teoria e prática. Com os resultados das análises, buscamos novos horizontes, os quais nos possibilitassem, neste texto, apresentar suas bases de sustentação para, em seguida, analisar como tem se apresentado a gestão democrática na área e, finalmente, responder à questão posta no início do texto. Encontramos em Gallo $(2007,2010)$ fundamentos para nossa compreensão das relações teoria e prática que, para ele, foram transportadas da Filosofia para a Educação e, para nós, serão transportadas destas para a Política e Administração/ Gestão da educação e escolar.

$\mathrm{O}$ autor identifica que teoria e prática foram trabalhadas no pensamento ocidental no âmbito da filosofia da representação, que delineou três perspectivas: 1. Idealista - totalização da teoria sobre a prática em que a filosofia, por exemplo, fundamentava a educação; 2. Materialista - totalização da prática sobre a teoria, cujo pressuposto é o de que a teoria apenas pode se construir com a vivência prática da realidade (no caso, escolar); 3. Dialética - a qual perspectiva uma interação entre teoria e prática. Apesar de embasamentos distintos, Gallo (2010, p. 59) destaca que todas estão "[...] delineadas no contexto de uma filosofia da representação, que toma a teoria como representação do real. O que fazem é propor distintas maneiras de pensar a relação da teoria com a prática, isto é, do ideal com o real, mas sem interferir na noção do ideal como representação do real." Ao contrário da tradição ocidental, ele se embasa em alguns autores da filosofia da diferença (DELEUZE, 1998, 2006; FOUCAULT, 1982) a qual apresenta uma noção distinta do platonismo e investe na produção de diferenças, centrando-se, também, na problemática da multiplicidade.

Para a filosofia da diferença, as relações teoria e prática já não fazem sentido, mas, sim, o "[...] primado da ação: ação de teoria, ação de prática em relações de revezamento.” (DELEUZE, 2006 apud GALLO, 2010, p. 54). Isto porque nessa perspectiva filosófica, as relações teoria e prática são consideradas parciais e fragmentadas porque se opõem à concepção de prática como aplicação da teoria ou daquela como inspiração para esta, pois, ambas, são totalizadoras.

O papel do intelectual também é revisto, uma vez que “já não se pode separar o intelectual, produtor de teorias, de um lado, e o militante, o ativista da prática, de outro. Ambos são a mesma pessoa, revezando-se nas diversas atividades." (GALLO, 2010, p. 57). Ele, o intelectual, não está à frente ou ao lado explicando a prática ou a prescrevendo, uma vez que nada é 
[...] mais indigno do que pretender falar por alguém, em pretender ser porta voz de qualquer classe ou grupo social. O intelectual é aquele que produz teorias - ferramentas - que servem ou não servem, que são ou não utilizadas, que entram ou não em revezamento com as práticas sociais, E o intelectual é aquele que está usando as ferramentas teóricas que cria, atuando na prática social (GALLO, 2010, p. 58).

Fundamentando-nos nessa perspectiva filosófica, podemos considerar o cotidiano escolar como "educação menor", aberto ao acontecimento, às diferentes e múltiplas vozes que dialogam na construção de relações pedagógicas. Ele - o cotidiano como educação menor - não quer se fazer modelo porque vale para o momento, no acontecimento. Já a "educação maior" apresenta "protocolos definidos" para ações e relações do cotidiano, "[...] são totalizações da teoria ou totalizações da prática, mas sempre totalizações e imposição de modelos. Neste registro, a criança não pode mesmo ser ouvida, ou sua voz faria ruir o castelo de cartas dos planejamentos e políticas públicas" (GALLO, 2010, p. 61).

Do exposto, compreendemos que a filosofia da diferença não nega a existência ou mesmo a necessidade de políticas públicas que garantam direitos conquistados e a conquista referentes à educação escolar, mas potencializa o âmbito do cotidiano escolar, cujo sabor das lutas encontra-se no acontecimento, no imprevisto, no instituinte e nas vozes que o constituem. Para a filosofia da diferença, o desafio está em “[...] investir em um pensamento criativo, para além das totalizações" e também na "[...] criação de novas práticas que ousem ouvir as crianças com ouvidos inocentes." (GALLO, 2010, p. 62).

Em seguida, importa-nos analisar como as relações teoria e prática são perspectivadas no âmbito das pesquisas com a temática gestão democrática para, em seguida, discutir os conceitos que nortearam nossa construção: Política e Democracia.

\section{A temática Gestão democrática no discurso da Administração/Gestão da educação}

No âmbito do projeto integrado citado na Introdução, duas pesquisas foram desenvolvidas, com bolsa da Fundação de Amparo à Pesquisa do Estado de São Paulo (FAPESP), tendo como objetivo analisar a produção do conhecimento sobre a temática gestão democrática em teses, dissertações e artigos publicados em periódicos qualificados (CARVALHO, 2017; PAREDES, 2017). 
As pesquisadoras partiram da hipótese do grupo maior que era a de que existem elementos constitutivos da teoria que a impedem de voltar-se para si, em um processo autocrítico, no sentido de lançar novos horizontes para seu modo de pensar o conhecimento e sua própria construção. Tal hipótese foi construída com nossos estudos anteriores sobre a trajetória do conhecimento em Administração/Gestão escolar e corroborada com a tese de Souza (2006), que realizou levantamento e análise das pesquisas de mestrado e doutorado dos Programas de Pós-graduação em Educação do país, entre os anos 1987 e 2004. Segundo Souza (2006, p. 122), o maior problema da produção se refere à “[...] ênfase por vezes um tanto normativa de vários trabalhos sobre gestão escolar" [...] que se "dedicam mais a demonstrar como a escola deve se organizar para ser democrática e menos a descrever e analisar como tem se organizado a gestão da escola, democrática ou não.” As pesquisas sobre gestão democrática são qualitativas, na maioria das vezes estudos de caso que, apesar de transgredirem com a forma dos escritos até os anos 1980, não rompem com a prescrição porque

[...] ao irem até a escola para analisar sua gestão, acabam por vezes mais preocupados em ou relatar experiências (bem) sucedidas de gestão (o que em si não é um problema) ou, de outro lado, terminam por apresentar um receituário de como as coisas deveriam ocorrer para o bom funcionamento (leia-se: democrático) da instituição escolar (SOUZA, 2006, p. 122).

Muito próximo de nossas constatações, o autor diz que a pesquisa na área da gestão escolar caminhou, em uma primeira fase, pela tentativa de sua profissionalização, com ênfase na teoria geral da administração de empresas e, posteriormente, perspectivou "[...] um futuro mais democrático", no entanto, "[...] esse suposto por-vir parece ainda não vingado, ao menos na investigação científica", pois permanece em "compasso de espera por novas teorias." (SOUZA, 2006, p. 122).

As constatações de Souza (2006) e nossa hipótese nortearam o desenvolvimento das pesquisas de Carvalho (2017) e Paredes (2017). A primeira analisou 11 teses e dissertações ( 9 dissertações e 2 teses) encontradas na biblioteca do Instituto Brasileiro de Informação de Ciência e Tecnologia (IBCTI), tendo como palavra-chave de busca "gestão democrática da escola pública"; a segunda analisou 23 artigos publicados em periódicos qualificados (entre A1 e B2), tendo feito a busca com a mesma palavra-chave da pesquisadora anterior.

Carvalho (2017) analisou as dissertações e as teses sob o respaldo teórico de Lopes (2006) que explorou a produção na área do Currículo a partir das rela- 
ções dos contextos "macro" e "micro" para compreender como e se as pesquisas estabelecem relações causais entre ambos. As constatações de Lopes (2006) no campo do Currículo foram semelhantes às constatações de Carvalho (2017) no campo da Administração/Gestão escolar ao indicarem "[...] a presença da dicotomia macro e micro e as relações causais estabelecidas entre esses níveis.". Além disso, foi constatado, nas dissertações e teses analisadas, que "[...] a teoria assume uma posição de exterioridade em relação àquilo que analisa" e, nesse sentido, "[...] nota-se um fechamento sobre si mesma que leva a práticas que a impedem de ver outros elementos que escapem aos seus esquemas conceituais." (CARVALHO, 2017, p. 65). A autora indica que sentia uma falta de expectativa quanto ao que leria nas pesquisas (uma vez que fez a leitura integral na sequência cronológica) porque a lógica que as sustentava era muito semelhante: práticas de pesquisa que buscavam analisar a gestão democrática como definida na lei e com possibilidades ou não de serem implementadas pelas escolas, ou seja, práticas de pesquisas que "cortam" a realidade em duas formas, sendo uma invariante (macro, universal, a ser aplicada, a Lei) e outra variante, que comporta particularidades (contextos locais, identidade da escola) que acabam subsumidas e adequadas ao esquema maior. A autora finaliza com uma questão bastante interessante que vem somar às nossas análises anteriores: "Qual pode ser a função de uma teoria que se questiona da materialização de um absoluto em diferentes lócus específicos? E mais ainda: denuncia sentidos errados de uma forma correta?" E responde: “Talvez reprovações daquilo que não devolve a sua imagem seguida da validação de si mesma.” (CARVALHO, 2017, p. 67).

Paredes (2017), partindo da mesma hipótese do grupo e com o objetivo de Carvalho (2017), fez o levantamento, sistematização e análise de 23 artigos publicados em periódicos classificados entre os estratos A1 e B2 (2005 e 2014). Sob o respaldo teórico-metodológico de Laclau e Mouffe (2015), a autora constatou que, em todos os artigos, estão presentes a discussão sobre o modo de produção capitalista e, também, a relação direta entre o trabalho do diretor de escola e a precarização do ensino, a falta de participação e a exclusão dos sujeitos da escola devido ao sistema econômico excludente. Paredes (2017) identifica a presença de um discurso hegemonizado constituído pela presença repetida das relações diretas entre política educacional e implementação pela escola; gestão democrática e eleição de diretores; gestão democrática e partidos políticos. Dessa forma, "a posição hegemonizada na área e possível de ser detectada da leitura do material empírico é aquele que associa gestão democrática à execução da Lei (BRASIL, 1988, 1996), à implantação de conselho de escola e eleição de diretores e à política democrática específica.” (PAREDES, 2017, p. 72). Cabe destacar que apenas em 2 artigos não esteve presente a proposição de uma verdade a ser seguida (implementada pela escola) ou, inclusive, um receituário 
a ser seguido para o sucesso da equipe de gestão da escola, fato comprovado pela autora ao destacar palavras repetidas presentes nos textos, como: "a escola deve"; "somente se o diretor da escola fizer"; "é preciso implementar" e/ou "só assim é possível." Finalmente, a autora identifica em 10 artigos a associação direta (causalidade) entre partido político no comando do governo federal, estadual ou municipal e a vivência de uma escola mais autônoma e democrática.

Bem, o que as pesquisas relatadas indicam é a continuidade da tese defendida por Souza (2006), nos anos subsequentes à sua defesa. O conjunto de pesquisas publicado em dissertações, teses e artigos em Administração/Gestão escolar, sobre a temática gestão democrática, relata escolas bem-sucedidas ou indica como devem fazer para serem bem-sucedidas, estabelece uma relação causal e, enfim, manifesta uma relação teoria e prática por representação (GALLO, 2010), contrária àquela que defendemos anteriormente.

A análise efetuada nos coloca alguns questionamentos: seria possível mobilizarmos outros referenciais para o estabelecimento de novas relações entre teoria e prática? Seria possível construirmos conceitos no campo da Administração/Gestão escolar que dessem conta de nos fornecer novos horizontes para as relações de revezamento?

\section{Teoria do Discurso: o Político, a Política e a Democracia radical e plural}

Ao mobilizar as categorias "articulação", "discurso", "hegemonia", "diferença", "equivalência", entre outras, a Teoria do Discurso (TD), construída por Laclau e Mouffe (2015) e já utilizada por autores da Educação, especificamente da Política e Gestão da educação (MARQUES, 2006, 2008, 2009), contribui para explicar a "totalidade discursiva" sobre a temática gestão democrática traçada anteriormente, a qual se caracteriza por constituir relações de representação teoria e prática.

Para os autores, discurso é a totalidade estruturada por uma "prática articulatória", sendo esta o estabelecimento de uma relação entre "elementos" os quais têm sua identidade modificada pela "prática articulatória". As "posições diferenciais" que aparecem articuladas no interior do discurso são chamadas de "momentos" e aquelas diferenças que não estão articuladas são denominadas "elementos". Laclau e Mouffe (2015) identificam alguns aspectos importantes que fundamentam a TD: 
a) "uma formação discursiva não é unificada pela coerência lógica de seus elementos", ou seja, ela se constitui como regularidade em dispersão, sendo esta última governada por certas regras. Dessa forma, “[...] numa totalidade discursiva articulada, em que todo elemento ocupa uma posição diferencial - em nossa terminologia, em que todo elemento é reduzido a um momento desta totalidade -, toda identidade é relacional e todas as relações têm um caráter necessário" (LACLAU; MOUFFE, 2015, p. 179);

b) ela rejeita a diferença entre práticas discursivas e práticas não discursivas, pois considera que todo objeto é constituído como objeto do discurso e não se constitui - o objeto - fora de uma condição discursiva. Dessa forma, a TD afirma o caráter material de toda estrutura discursiva, tendo como consequência principal "[...] o abandono da oposição pensamento/realidade, e, portanto, um maior alargamento do campo das categorias que podem dar conta das relações sociais;

c) a totalidade relacional - o discurso - apresenta limitação uma vez que a lógica relacional é incompleta e atravessada por contingência e, sendo assim, nenhuma identidade pode ser plenamente constituída e a totalidade discursiva é incompleta e passível de modificação a partir de novas articulações;

d) o caráter incompleto da totalidade discursiva faz com que a TD abandone “[...] como terreno de análise, a premissa da sociedade como uma totalidade suturada e autodefinida. Sociedade não é um objeto válido de discurso. Não há um princípio singular subjacente fixando - e, portanto, constituindo - o campo das diferenças como um todo." (LACLAU; MOUFFE, 2015, p. 185);

e) a totalidade discursiva - que é parcial - tem a tentativa de dominar o campo da discursividade e de construir um centro, denominado pela TD como "pontos nodais", que são os pontos discursivos privilegiados pela fixação parcial.

Vejamos como é pertinente analisar a "totalidade discursiva" - que denominaremos de discurso sobre gestão democrática - produzida pela área com as ferramentas da TD. Os aspectos elencados nos itens a), b) e e) nos permitem inferir que a "gestão democrática" é produzida pela "totalidade discursiva" que a constitui, ou seja, a prática articulatória que identifica elementos e os transforma em momentos de uma totalidade fixada parcialmente. Este discurso é constituído com regras próprias, que são a separação entre teoria e prática; a separação entre a legislação e a escola; a construção de verdades teóricas para a ação nas escolas, isto, portanto, constitui-se como gestão democrática: o ideal que, um dia, quem sabe, será vivenciado pelo real (as escolas com todas as suas especificidades). Como ponto nodal discursivo temos a gestão democrática ideal - estabelecida pela Constituição Federal Cidadã e pela Lei de Diretrizes e Bases da Educação Nacional, e também pelas teorias da área baseadas no marxismo - e a gestão da escola pública, real, que não atinge o delineamento teórico e o posto pela legislação. 
Os itens c) e d) nos permitem, com Laclau e Mouffe (2015), perspectivar novas possibilidades para o discurso que é a negação da gestão democrática (no caso deles, a sociedade) como categoria autodefinida e/ou suturada e poderíamos pensar em novas articulações que não aquelas estabelecidas pela totalidade discursiva apresentada. Para isto, teríamos que perguntar: o que não está sendo articulado na prática articulatória que constituiu, até o momento, o discurso sobre gestão democrática? Neste momento, poderíamos responder que, talvez, o elemento ainda não transformado em momento pela prática articulatória dos pesquisadores é o estabelecimento de novos horizontes de relacionamento entre teoria e prática em que, necessariamente, haverá a subversão da hierarquia entre ambas.

A TD traz também alguns conceitos interessantes que podem contribuir com essa nova prática teórica: o Político, a Política e a Democracia radical e plural, os quais, nos limites do texto, serão trabalhados a seguir, somando ao raciocínio desenvolvido que culminará na resposta à questão posta no início do texto.

No discurso da área da Política e Administração/Gestão da educação e escolar, são comumente aceitas como explicações conceituais a "Política Educacional" como o funcionamento das "políticas educacionais", e estas como ações de um determinado governo (que também e muitas vezes contam com a participação da sociedade civil), voltadas para as diferentes etapas do ensino. No que se refere à "gestão", ela é conceituada como a materialização das diferentes políticas educacionais, ou seja, a implementação das políticas (VIEIRA, 2006). Os adjetivos somados aos substantivos (educacional e escolar) apenas indicam a amplitude da política e da gestão: educacional - sistema e escolar - unidade. Nessa explicação conceitual encontramos os fundamentos para a lógica que constitui, também, o discurso sobre gestão democrática.

Na perspectiva filosófica explorada por nós, neste texto, ao contrário, identificamos a política com as diferentes práticas da política convencional, e o político com a forma em que a sociedade é fundada. Assim, no político está presente a dimensão do antagonismo que é " [...] constitutiva das sociedades humanas" e na política está presente "[...] o conjunto de práticas e instituições por meio das quais uma ordem é criada, organizando a coexistência humana no contexto conflituoso produzido pelo político." (MOUFFE, 2015, p. 8).

Ampliamos, dessa forma, a compreensão da política para além das diretrizes governamentais e a inserimos como também constituindo as relações sociais (permeada pelo político) no interior das instituições, como a escola. Com a autora, reforçamos a ideia de que as questões políticas envolvem decisões sobre alternativas que são conflitantes, ou seja, elas são permeadas por antagonismo o qual revela, ao contrário do que propõem as propostas liberais de democracia 
- modelos agregativo e deliberativo -, o limite de qualquer consenso racional. Ora, na perspectiva de Mouffe (2015), as identidades (individuais e coletivas) se constituem a partir de relações com posições diferenciais e, consequentemente, produzem o "nós" e o "eles", sendo a tarefa da política democrática "[...] não a superação da oposição nós/eles, mas a forma diferente pela qual ela se estabelece. O que a democracia exige é que formulemos a distinção nós/eles de um modo que seja compatível com a aceitação do pluralismo, que é constitutivo da democracia moderna." (MOUFFE, 2015, p. 13). Caminhando por esse raciocínio, podemos dizer que compete à política democrática transformar antagonismos em agonismos que dizem respeito, especificamente,

[...] a uma relação nós/eles em que as partes conflitantes, embora reconhecendo que não existe nenhuma solução racional para o conflito, ainda assim reconhecem a legitimidade de seus oponentes [...]. Poderíamos dizer que a tarefa da democracia é transformar antagonismos em agonismo. (MOUFFE, 2015, p. 19).

Explorando a epígrafe deste artigo, podemos dizer que, nessa perspectiva, as instituições democráticas, como a escola, são locais que proliferam a constituição do "eu" e "ele" ou do "nós" e "eles" e sua tarefa é fazer aparecer essas relações antagonísticas, transformando-as em relações angonísticas. Os antagonismos não desaparecerão... não haverá consenso... mas este não é o problema. O problema é acharmos que o consenso é possível! É preciso explicitar posições para que se possa constituir decisões e novas posições, em um continum de processos hegemônicos. Dessa forma, nos aproximaríamos da perspectiva de democracia radical e plural a qual preza pela multiplicidade e pluralidade como fundamento de sua existência (LACLAU; MOUFFE, 2015).

Para nós, pesquisadores, ficam algumas questões importantes, entre elas: quais são as condições que fazem emergir relações próprias da política democrática? Por exemplo: quais foram as condições de emergência das equivalências no processo de resistência à política governamental paulista de fechamento das escolas? Refiro-me, aqui, às ocupações das escolas estaduais. Este tipo de pergunta feita por pesquisadores pode trazer à tona problemas que nos permitam estabelecer novas relações entre teoria e prática, constituídas por revezamento e não por representação. Este tipo de pergunta nos leva a abrir-nos ao cotidiano da escolar para compreendermos seu potencial de resistência por meio dos seus acontecimentos. 
Estar atento àquilo que ocorre no cotidiano da escola, a fim de potencializá-lo criativamente, e não ser tragado, engolido pelo acontecimento. Perder-se no acontecimento, não conseguindo produzir, é tão ruim quanto estratificá-lo, fazê-lo perder a potência, dominando os fluxos e reenquadrando as diferenças na norma. Resistir e criar. Essas são as possibilidades que nos abre o cotidiano da escola, quando escolhemos agir no fluxo do acontecimento. (GALLO, 2007, p. 39).

\section{Considerações finais}

Sendo parte integrante do Dossiê que discute a gestão da escola pública, em particular a temática gestão democrática, este artigo teve como objetivo contribuir com o debate na área da Política e Administração/Gestão da educação e escolar, trazendo uma reflexão específica sobre as relações teoria e prática estabelecidas pelos pesquisadores da área. Nosso objetivo, portanto, foi o de nos provocar no sentido de (re)pensar nossa função e nossas práticas de pesquisa.

Meu ponto de partida foi uma questão posta em uma das mesas temáticas que participei - "você considera que seria bom que o governo federal aprovasse uma lei que regulamentasse a gestão democrática no âmbito dos governos e das escolas?" -, seguida de três partes que integradas me permitirão respondê-la. Destaco que a resposta à questão - sim ou não - pode parecer simples, mas o arcabouço teórico construído me permitirá demonstrar que a simplicidade da resposta explicita todo um posicionamento dos pesquisadores da área e sua construção hegemônica.

Se a resposta fosse sim, o governo federal deveria aprovar uma lei que pudesse organizar a escola em um regime democrático, explicitaria a posição hegemonizada pelos pesquisadores da área os quais estabelecem a relação teoria e prática por representação. Ou seja, com a lei e por ela, as escolas teriam maiores chances - ou talvez a obrigação - de cumprirem a gestão democrática. Ora, já não é suficiente para demonstrar que essa assertiva não é procedente pelo conjunto de textos analisados em formas de dissertações, teses, artigos e livros que destacam o não exercício da gestão democrática como posta na Constituição Federal e na Lei de Diretrizes e Bases da Educação Nacional, ou mesmo em legislação específica dos estados e municípios? Por que e apesar disso continuamos insistindo na mesma forma de produzir conhecimento? Por que não mudamos nossos problemas de pesquisa para que possamos enxergar o que ainda não enxergamos? 
Pois bem, minha resposta foi não. Naquele momento, apenas disse que não tenho um pensamento modelar e defendo que modelos não dão conta de serem aplicados, pois anulam a multiplicidade e matam os acontecimentos. Após o percurso teórico deste texto, reforço a ideia do não: princípios, fundamentos e práticas padronizadas sobre gestão democrática advindos do governo federal - porque não dizer dos pesquisadores - não mudariam a escola, não a transformariam em uma escola democrática. Talvez, apenas reforçariam aquilo que os profissionais e a comunidade escolar que estão lá presentes cotidianamente estão cansados de ouvir: vocês não sabem, vocês não fazem, aqui não tem democracia. Minha resposta é reforçada quando pensamos no atual Plano Nacional de Educação, objeto de análise do próximo artigo, que estabelece como obrigatória a construção, pelos estados e municípios, de uma lei sobre gestão democrática: quantos a fizeram? E aos que fizeram, podemos fazer a pergunta: quais são as pessoas que estão na escola que conhecem a lei? Para que ela serve? O que efetivamente ela muda?

A resposta negativa nos impõe, finalmente, uma obrigação de mudança de nossas práticas teóricas, estas precisam se abrir, criar, perspectivar novos horizontes que nos possibilitem escapar do vai e vem do movimento linear da teoria para a prática, da prática para a teoria, do ideal para o real. Não é uma tarefa simples, mas este problema vem incomodando os integrantes do nosso grupo de pesquisa há alguns anos e procuramos multiplicar nossas preocupações para que juntos possamos pensar em alternativas viáveis para o avanço do conhecimento na área da Política e Administração/Gestão da educação e escolar.

\section{REFERÊNCIAS}

ABDiAN, G. Z.; NASCIMENTO, P. H.C.; SILVA, N. D. B. da. Desafios teórico-metodológicos para as pesquisas em administração/gestão educacional/escolar. Educ. Soc., Campinas, v. 37, n. 135, p. 465-480, abr.jun. 2016.

ABDIAN, G. Z.; NASCIMENTO, P. H.C. Gestão e qualidade da educação escolar básica: sentidos em construção. Espaço Pedagógico, Passo Fundo, v. 24, n. 3, p. 295-313, maio/ago. 2017.

ABDIAN, G. Z.; ANDRADE, E.; PARRO, A. L. G. Sentidos de política e/de gestão nas pesquisas sobre a escola. Educ. Pesqui., São Paulo, v. 43, n. 3, p. 727-742, jul./set. 2017.

BOURDIEU, P. Os usos sociais da ciência: por uma sociologia clínica do campo científico. Trad. Denice B. Catani. São Paulo: Editora UNESP, 2004. 
CANÁRIO, R. A escola tem futuro? Das promessas às incertezas. Porto Alegre: Artmed, 2006.

CARVAlHO, M. G. de. Teses e dissertações sobre gestão escolar democrática no Brasil: análise a partir da metapesquisa (2005-2014). 2017. Trabalho de Conclusão de Curso (Pedagogia) - Faculdade de Filosofia e Ciências, Universidade Estadual Paulista, Marília. 2017.

DELEUZE, G. Lógica do Sentido. 4. ed. São Paulo: Perspectiva, 1998.

DELEUZE, G. Diferença e Repetição. 2. ed. Rio de Janeiro: Graal, 2006.

FOUCAULT, M. Microfísica do poder. 3. ed. Rio de Janeiro: Edições Graal, 1982.

GALLO, S. Acontecimento e resistência: educação menor no cotidiano da escola. In: CAMARGO, A. M. F. de; MARIGUELA, M. (Orgs.). Cotidiano escolar: emergência e invenção. Piracicaba: Jacintha Editores, 2007. p. 21-40.

GALLO, S. Filosofias da diferença e Educação: o revezamento entre teoria e prática. In: CLARETO, S. M.; FERRARI, A. (Orgs.). Foucault, Deleuze e Educação. Juiz de Fora: Ed. UFJF, 2010.

GALLO, S.; FIGUEIREDO, G. M. Entre maioridade e menoridade: as regiões de fronteiras no cotidiano escolar. Aprender - Cadernos de Filosofia e Psicologia da Educação, Vitória da Conquista, ano IX, n. 14, p. 25-51, 2015.

LACLAU, E.; MOUFFE, C. Hegemonia e estratégia socialista: por uma política democrática radical. Tradução Joanildo A. Burity, Josias de Paula Jr. e Aécio Amaral. São Paulo: Intermeios; Brasília: CNPq, 2015. (Coleção Contrassensos).

LOPES, A. C. Relações macro/micro nas pesquisas em currículo. Caderno de Pesquisa, São Paulo, v. 36, n. 129, p. 619-635, set./dez. 2006.

MARQUES, L. R. A descentralização da gestão escolar e a formação de uma cultura democrática nas escolas públicas. 288 f. 2006. Tese (Doutorado) - Programa de Pós-Graduação em Sociologia, Universidade Federal de Pernambuco, Recife. 2006.

MARQUES, L. R. Democracia radical e democracia participativa: Contribuições teóricas à análise da democracia na educação. Educ. Soc., Campinas, v. 29, n. 102, p. 55-78, jan./abr. 2008.

MARQUES, L. R. Mudanças discursivas nas políticas de democratização da educação. R. Bras. Est. pedag., Brasília, v. 90, n. 225, p. 468-488, maio/ago. 2009.

MOUFFE, C. Por um modelo agonístico de democracia. Revista de Sociologia e Política, Curitiba, n. 25, nov. 2005.

MOUFFE, C. Sobre o político. Trad. Fernando Santos. São Paulo: Editoria WMF Martins Fontes, 2015. 
PAREDES, C. G. Publicações sobre gestão escolar democrática: análise a partir da metapesquisa (2005-2014). Relatório de Pesquisa (Iniciação científica). Fundação de Amparo à Pesquisa do Estado de São Paulo (FAPESP), 2017. 80 p.

SOUSA SANTOS, B. de. Por que é tão difícil construir uma teoria crítica? Revista Crítica de Ciências Sociais, n. 54, p. 197-215, 1999.

SOUZA, A. R. de. Perfil da gestão escolar no Brasil. 185 f. 2006. Tese (Educação) Pontifícia Universidade Católica de São Paulo, São Paulo. 2006.

VIEIRA, S. L. Política(s) e gestão da educação básica: revisitando conceitos simples. RBPAE, v. 23, n. 1, p. 53-69, 2006.

Texto recebido em 18 de janeiro de 2018. Texto aprovado em 30 de janeiro de 2018. 